\title{
The Effect of Waste Tyre Steel Fibers distribution Characteristics on the Flexural Strength of Concrete with Improving Environmental Impact in Pakistan
}

\author{
Rizwan Hussain Wagan ${ }^{1}$, Farhan Hussain Wagan ${ }^{2}$, Imran Hussain Wagan ${ }^{3}$, \\ Ghulam Hussain Wagan ${ }^{4}$ \\ ${ }^{1}$ Sindh Building Control Authority, Government of Sindh, Sindh, Pakistan \\ ${ }^{2}$ Department of Irrigation, Government of Sindh, Sindh, Pakistan \\ ${ }^{3}$ Civil Engineering Department, Quaid-e-Awam University, Nawabshah, Sindh, Pakistan \\ ${ }^{4}$ Department of Civil Engineering, Swedish Engineering College, Raheem Yar Khan, Punjab, Pakistan
}

Email address:

farhan_hussain_4u@yahoo.com (F. H. Wagan)

\section{To cite this article:}

Rizwan Hussain Wagan, Farhan Hussain Wagan, Imran Hussain Wagan, Ghulam Hussain Wagan. The Effect of Waste Tyre Steel Fibers distribution Characteristics on the Flexural Strength of Concrete with Improving Environmental Impact in Pakistan. American Journal of Applied Scientific Research. Vol. 3, No. 5, 2017, pp. 49-55. doi: 10.11648/j.ajasr.20170305.11

Received: March 20, 2017; Accepted: April 14, 2017; Published: November 28, 2017

\begin{abstract}
The use of vehicles in Pakistan is increasing day-by-day because of which disposal of solid waste to the landfills of used tyres is a serious issue to be solved for Pakistan EPA. Currently this industry is facing many challenges due to lack of support from government for the recycling and reuse of waste tyre by products but manually a large quantity of high strength steel fibers are being extracted from waste tyres, the dominant use of this tyre-derived fiber is a scrap steel to manufacture new iron or steel. This research study is focusing on the use of steel fibers extracted from waste tyres in concrete with different proportions to produce a concrete more strong than ordinary concrete (specially as a member like Beam) economical and cost effective. Different concrete specimens were fabricated and tested in uniaxial compression testing machine to find compression and splitting Beams for the Flexural Strength. The steel fibers were substituted into the concrete by dry weight of mix with $0 \%$, $0.5 \%, 1 \%, 1.5 \%, 2 \%$ and $2.5 \%$. Result shows that the flexural strength of concrete with $2.5 \%$ fibers improved up to $74 \%$.
\end{abstract}

Keywords: Waste Tyre Steel Fibers, Concrete, Flexural Strength, Moment of Inertia, Modulus of Elasticity, Results and Discussions

\section{Introduction}

These fibers are produced in the industries for special tasks with different sizes and shapes. These are available in markets with various weights of bags mostly in $10 \mathrm{~kg}$ bags. Steel fibers are being produced by the developers for the use in concrete to form a composite concrete mix for the improvement of weak parameters of concrete, but mostly the researchers have used industrially produced steel fibers for the improvement of these characteristics of concrete. The concrete mix made of these fibers is abbreviated as (IPSFC).

There are many types of steel fibers being industrially produced for the improvement of various weak parameters of concrete such as post-cracking mechanical behavior, toughness, impact resistance, tensile and flexural strength and also the durability of reinforced concrete structures. These fibers are costly and uneconomical to be used in every structural work because most of the clients cannot afford their cost which limits their application for construction.

\section{Waste Tyre Steel Fibers}

Used/waste tyres in Pakistan is one of the cheap, economical, easy and abundantly available source for producing a high tensile strength steel fibers known as RTC (Recycled tyre cord), which can be used successfully in the concrete mix. Recently few researcher have carried research on used tyres steel fibers concrete and the results seems to be satisfactory, but it needs more research work to authenticate 
the outcomes.

Due to lack of recycling industry of used tyres in Pakistan, these days manually a large quantity of steel fiber is being extracted which contains some amount of rubber particles on their surfaces. These fibers can be used either along the rubber particles on its surface or these rubber particles can be separated by controlled temperature in absence of oxygen. Then these fibers are cut at specific aspect ratios and can be used in concrete mix. In this experimental work tyre chips were being burnt to separate the rubber particles. Burning slightly affected the strength properties of these steel fibers.

\section{Problem Statement}

Facts and figures show that concrete is a brittle material and has negligible tensile and flexural strength. Concrete fails mostly due to the tensile stresses produced in it due to its self-weight or after the application of superimposed loads, in this regard heavy conventional reinforcement in the form of steel bars of different grades is provided at the tensile stressed zones of the concrete structural members which further increase the self-weight of the structure. Hence, these weak parameters such as tensile and flexural strength and also brittle nature of concrete can be improved by substituting the steel fibers to the concrete mix with definite proportion. These steel fibers serve the function of interlocking and transferring loads. This composite fibrous concrete mix can be used in conventional RCC structures like plain concrete mix.

\section{Aims and Objectives of Research}

The aim of this research is to investigate the effect of introducing the used tyres steel fibers in concrete, on compressive and tensile strength and to compare cost of WTSFC with SFC, by considering market rate of available steel fibers of same size and to provide additional environmental benefits by reducing solid waste, also to produce strong and economical concrete as compared to ordinary concrete with optimum proportion of waste tyres fibers.

\section{Literature Review}

Adding a small quantity of steel fibers into an ordinary concrete mix does not require special tools or working procedures, nor does it significantly affect concrete workability and productivity. However, a notable increase in performance may be expected in its hardened state. [1] The results of the laboratory work showed that replacement of fly ash with cement reduced abrasion resistance of concrete; however, inclusion of the steel fiber improved the abrasion resistance of concrete. Using polypropylene fiber did not improve abrasion resistance of concrete made with or without fly ash [2] recently some research has been devoted to the use of granulated rubber and steel fibers recovered from waste tyres in concrete. In particular, the concrete obtained by adding recycled steel fibers evidenced a satisfactory improvement of the fragile matrix, mostly in terms of toughness and post cracking behavior. As a consequence RSFRC (recycled steel fibers reinforced concrete) appears a promising candidate for both structural and non-structural applications. [3]

Addition of fibers has been shown to increase the flexural strength, and ductility of structures, but few such research studies have been undertaken to examine the role of fibers in the area of prestressed concrete applications. This aspect is very important in applications where the serviceability in terms of limits on the deflection and crack width controls the design [4] In the past decade, considerable research programs have been conducted to validate the application of FRP composites in the construction industry, and recently, structural applications of FRP materials have begun to appear in different types of the concrete structures. To most effectively utilize the advantages of FRP materials, innovative structural systems are needed which either incorporate "composite-efficient" forms or which combine these "new" materials with conventional ones [5].

The most important advantages of fiber reinforced concrete are increased tensile strength and improved toughness. Furthermore, it improves shear strength, increases the resistance against dynamic load, and reduces shrinkage cracking [6] In particular the concrete obtained by adding recycled steel fibers showed a good improvement of the brittle matrix, especially in terms of toughness and postcracking behavior, as widely already experienced for ISFRC (Industrial Steel Fibers Reinforced Concrete). In fact it is well known that the dispersion of steel fibers in concrete allows a noticeable improvement of the concrete mechanical properties, mostly in terms of dynamic and fatigue resistance, shear and post-cracking strength [7] In fact, the existing rules for conventional concrete can hardly be adopted for fiber reinforced concrete that is markedly nonlinear since fibers start working after cracking of the concrete matrix. While conventional reinforced concrete keeps a reasonable linear behavior until the bars yield, fiber reinforced concrete has a noticeable nonlinear response and, depending on the fiber reinforcement (content and type), fiber reinforced concrete has a quite complicated post cracking softening behavior [8] A comparative evaluation of the fatigue properties was reported for concretes without and with four types of fibers (hooked-end, straight, corrugated, and polypropylene) at two different volume fractions of $0.5 \%$ and $1.0 \%$ using the same mix proportions for all the concretes. It was observed that the addition of all the four types of fibers caused considerable increase in the flexural fatigue strength and endurance limit, with the hooked-end steel fibers providing the highest improvement $(143 \%)$ and that the straight and the polypropylene fibers providing the least [9] The use of steel fibers in concrete significantly increases the flexural strength of the material. Furthermore, the increase of the flexural strength of SFRC is significantly improved with increasing the fiber aspect ratio (i.e. fiber length/fiber diameter ratio) and fiber volume fraction [10]. 


\section{Functions and Properties of WTSF}

As waste tyres fibers are uniformly distributed throughout the concrete mix. The basic function of steel fibers in concrete mix is to modify micro and macro cracking. These steel fibers resist crack growth by intercepting cracks at their basics. For this reason the temperature and shrinkage cracks which are controlled by the welded wire reinforcement can be replaced by WTSF. Steel fibers can be added to the mix at the plant or at site at the time of mixing concrete.

Generally the steel fibers mix can be pumped for placing like concrete without fibers, but special care should be taken so that fibers from balling action should be prevented. However in Pakistan the main issue for the use of industrially-produced steel fibers reinforced concrete mix is its high cost, which restricts the extensive use of SFRC in the construction. In this specific research study steel fibers extracted from waste tyres are introduced in the matrix material (concrete) to form a fibrous composite abbreviated as WTSFC. This composite matrix performs the several tasks, including, controls the shrinkage cracking on the surface of concrete, binding the fibers together and transferring loads to the fibers. Maximum cut length of the fibers were kept 1" with the ratio (Length/Diameter) equal to 90.

\section{Flexural Strength}

Flexural Strength, also known as Modulus of rupture internal resistance in material which trying to resist against deformation under load. Flexural strength is same as tensile strength if material is same. In our research we consider a

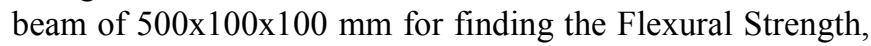
its formula is load multiply with length divides the width and twice of depth.

$$
\sigma=\mathrm{P} \times \mathrm{L} / \mathrm{b} \times \mathrm{d}^{2}
$$

Unit: MPa or $\mathrm{N} / \mathrm{mm}^{2}$.

Where $\mathrm{P}=$ load on beam, $\mathrm{L}=$ length of beam, $\mathrm{b}=$ breadth of beam, $\mathrm{d}=$ depth of beam.

\section{Moment of Inertia}

Some time, instead of force, area or mass of structural member is considered. Then the second moment is known as second moment of mass. So, all second moments are known as Moment of Inertia. Its unit is $\mathrm{mm}^{4}$ or $\mathrm{m}^{4}$. For rectangular section moment of inertia is $\mathrm{bd}^{3} / 12$. For circular section is

$$
\text { (pi/64) } \mathrm{x} \mathrm{d}^{4}
$$

Where $b=$ breadth of rectangular section, $d=$ depth of rectangular section. $d=$ dia of circular section.

\section{Modulus of Elasticity}

The static modulus of elasticity of concrete is calculated from the stress-strain curve obtained from the compression test under uniaxial loading. Methods of determining the Young's modulus of concrete are described in ASTM C 46974.

Stress is directly proportional to stress is known as Modulus of Elasticity.

$$
\mathrm{E}=\text { stress } / \text { strain }
$$

Where $\mathrm{E}$ is constant re-placing proportionality known as Young's modulus. Modulus of elasticity has no Unit.

The stress-strain relationship for concrete is obtained from compression tests on concrete specimens, cylinders, or cubes at the age of 28 days. In the United States, the standard test specimen used to determine $f c^{\prime}$ is 6 in 12 in cylinders. During testing, the strains are recorded at various loading increments until the cylinder ruptures. Compression test results are sensitive to the rate of loading - the slower the rate of loading, the larger the strain. Larger strains at failure occur because of the phenomenon of creep (discussed later), a time-dependent characteristic of concrete that causes strains in concrete under constant load or stress to increase with time.

Table 1. Data of Waste Tyres Steel Fibers.

\begin{tabular}{llll}
\hline Serial No & Diameter $(\mathbf{m m})$ & Length $(\mathbf{m m})$ & Ult. Strength (Mpa) \\
\hline 01 & 0.300 & 50 & 1309.34 \\
02 & 0.260 & 50 & 1309.22 \\
03 & 0.250 & 50 & 690.56 \\
04 & 0.290 & 50 & 1161.8 \\
05 & 0.290 & 50 & 1206.33 \\
06 & 0.300 & 50 & 914.1 \\
Average Size: & 0.280 & 50 & 1098.6 \\
\hline
\end{tabular}

Samples were taken, extracted from tyre chips by burning procedure and samples were extracted from tyre chips by rubbing rubber particles from the fiber surface and all these samples were presented for tensile strength test on Universal Testing Machine with Five ton capacity.

The test was conducted on them for a $50(\mathrm{~mm})$ length, their results are shown below in Table 2 .

Table 2. Shows Tesile Strength Test Results of Waste Tyre Steel Fibers.

\begin{tabular}{llllll}
\hline S. No & $\begin{array}{l}\text { Dia in } \\
\mathbf{m m}\end{array}$ & $\begin{array}{l}\text { Area } \\
\mathbf{m m}^{\mathbf{2}}\end{array}$ & $\begin{array}{l}\text { Elongation } \\
\text { in } \mathbf{~ m m}\end{array}$ & $\begin{array}{l}\text { Maximum } \\
\text { Force (N) }\end{array}$ & $\begin{array}{l}\text { Maximum } \\
\text { Stress (Mpa) }\end{array}$ \\
\hline 01 & 0.28 & 0.062 & 4.29 & 143.42 & 2329.184 \\
02 & 0.28 & 0.062 & 2.72 & 120.54 & 1957.606 \\
03 & 0.28 & 0.062 & 3.15 & 135.21 & 2195.851 \\
04 & 0.28 & 0.062 & 3.22 & 127.28 & 2067.065 \\
05 & 0.28 & 0.062 & 3.89 & 128.83 & 2092.238 \\
06 & 0.28 & 0.062 & 3.52 & 125.7 & 2041.406 \\
Average: & 0.28 & 0.062 & 3.47 & 130.16 & 2113.892 \\
\hline
\end{tabular}

\section{Batch Proportion}

Materials proportions used for the preparation of concrete mix are shown in the following table 3 . 
Table 3. WTSF Concrete mix Proportion by Weight.

\begin{tabular}{llll}
\hline $\begin{array}{l}\text { Water/cement } \\
\text { ratio }\end{array}$ & Cement & $\begin{array}{l}\text { Fine agg./cement } \\
\text { ratio }\end{array}$ & $\begin{array}{l}\text { Coarse agg./cement } \\
\text { ratio }\end{array}$ \\
\hline 0.55 & 01 & 02 & 04 \\
\hline
\end{tabular}

A mix having ratio of 1:2:4 by weight with water/cement ratio of 0.55 was used for this research study. The constituents of materials for mix were exactly calculated as per mix proportion.

Six batches of concrete prepared for specimens of $100 \mathrm{~mm}$ width, $100 \mathrm{~mm}$ depth and $500 \mathrm{~mm}$ length of Beam were casted. One batch was made without waste tyres steel fibers, to be the control while five batches were prepared using different proportions of waste tyres steel fibers. All Beams have been casted using steel fibers of lengths half inch and one inch length.

By using pan mixer, mix all ingredients of concrete including steel fibers of required size. Care should be taken while mixing of the fibers (at very low percentage) so that the uniform dispersion of fibers and prevent the segregation or balling of the fibers.

\section{Research Methodology}

Concrete is a mixture of cement, aggregates and water. Concrete plays an important role in the development of infrastructure Viz., industrial structures, bridges, highways and buildings. Leading to utilization of large quantity of concrete. West Tyre Steel Fiber addition in to concrete significantly improved the abrasion resistance of concrete. Abrasion resistance was found to increase with the increase of volume steel fiber. Although addition of west tyre steel fibers to concrete mix did not significantly improve its ultimate compressive strength, the addition of **WTSF and increasing the volume fractions of steel fiber increased flexural tensile strength.

Concrete is good in compressive strength but today west tyre steel fibers reinforced concrete is perhaps one of the most realistic possibilities to develop the use of concrete in load bearing structures.

\subsection{Casting of Test Specimens}

Seventy beams of size $(500 \times 100 \times 100) \mathrm{mm}$ were casted of 1 inch WTSF in length with proportion of $0 \%, 0.5 \%, 1 \%$, $1.5 \%, 2 \%, 2.5 \%$ and $3 \%$ by the weight of cement was used. The different proportions of materials were mixed in pan mixture machine and vibrating table was used for compaction of WTSF.

Procedure of mixing of concrete including WTS fibers is very simple as a plain concrete, putting dry material in concrete mixer and then 0.55 ratio of water with comparing to cement, $\mathrm{pH}$ value of concrete were tested for required potable water for concrete. Than mixing ingredients up to 1.5 to 2 minutes (some time according to proper mixing). After proper mixing slump test of plastic concrete for workability should be taken and temperature were also measured for the proper hydration of cement to check the quality of cement, then plastic concrete was putted in mould of Beam on vibration table, placing was done in three layers with ramming by rod ( 25 times each layer). Total 75 beams were casted.

\subsection{Testing Procedure}

There are a number of specific standardized testing procedures for determination of various properties of concrete. After being cured beams were tested for flexural strength on Universal testing machine (UTM) in the laboratory.

In the laboratory flexural strength test was conducted on Beam specimens.

Samples from each of the batches were tested. ASTM C C496-86 Standard was used in conducting flexural strength test.

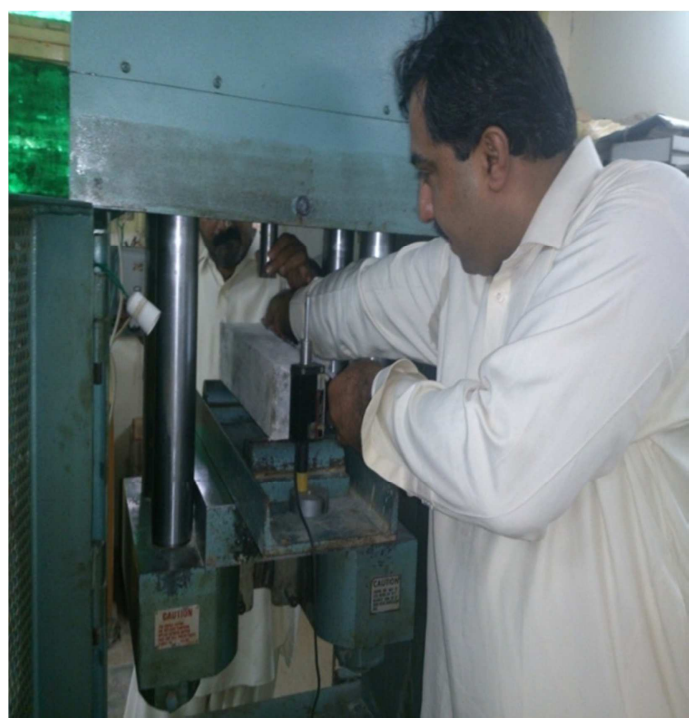

Figure 1. Adjustment of Beam in Testing Machine.

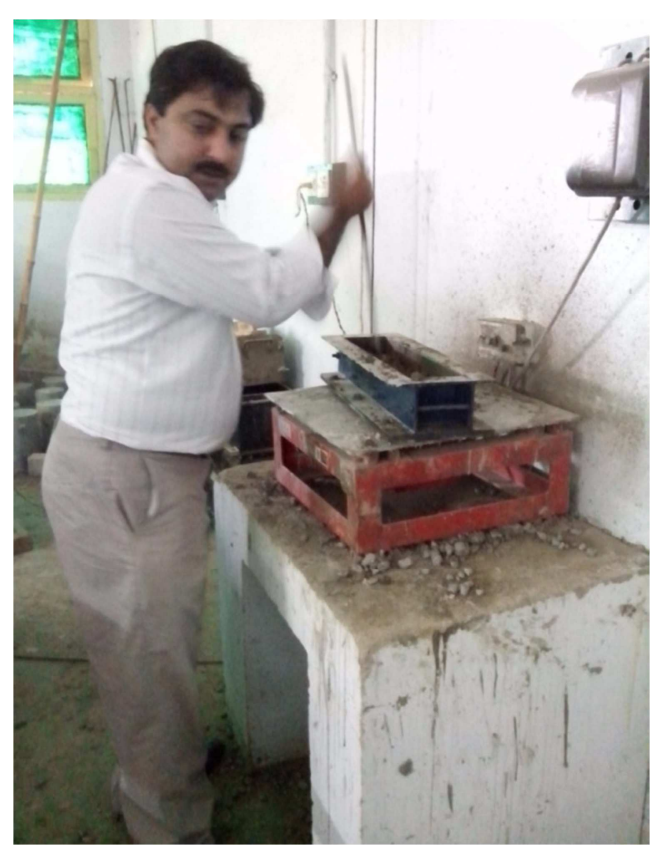

Figure 2. Manufacturing Procedure of Beam. 


\subsection{Test Specimens}

1. Total 70 Beam specimens casted (1:2:4 concrete mix with $w / c$ ratio 0.55 ).

2. 05 per batch.

3. Beam size $500 \times 100 \times 100 \mathrm{~mm}$.

4. Fiber Proportion $0 \%, 0.5 \%, 1 \%, 1.5 \%, 2 \%, 2.5 \%$ and $3 \%$.
5. Specimens Casting (Proportioning, Mixing, Placing, Compaction \& de-mould within 24 hours).

6. Curing -28 days.

7. UTM was used for Testing of samples.

8. Comparison ( $0 \%$ Steel fibers) conventional concrete was done with WTSFC.

Table 4. Flexural Strength of Specimen at Different Loads with Different Percentage of Waste Tyre Steel Fibers of 1 " size.

\begin{tabular}{|c|c|c|c|c|}
\hline Serial No & PERCENTAGE \% & No of BEAMS & FLEXURAL STRANGTH (MPa) & LOAD (kg) \\
\hline \multirow{5}{*}{1} & \multirow{5}{*}{$0 \%$ of $1 "$} & Beam1 & 0.335 & 475 \\
\hline & & Beam2 & 0.329 & 475 \\
\hline & & Beam3 & 0.325 & 350 \\
\hline & & Beam4 & 0.325 & 350 \\
\hline & & Beam5 & 0.325 & 350 \\
\hline \multirow{5}{*}{2} & \multirow{5}{*}{$0.5 \%$ of $1 "$} & Beam6 & 0.39 & 325 \\
\hline & & Beam7 & 0.455 & 325 \\
\hline & & Beam8 & 0.424 & 325 \\
\hline & & Beam9 & 0.44 & 325 \\
\hline & & Beam10 & 0.39 & 325 \\
\hline \multirow{5}{*}{3} & \multirow{5}{*}{$1 \%$ of $1 "$} & Beam11 & 0.4 & 425 \\
\hline & & Beam 12 & 0.45 & 475 \\
\hline & & Beam13 & 0.425 & 450 \\
\hline & & Beam14 & 0.45 & 475 \\
\hline & & Beam15 & 0.425 & 450 \\
\hline \multirow{5}{*}{4} & \multirow{5}{*}{$1.5 \%$ of $1 "$} & Beam16 & 0.45 & 475 \\
\hline & & Beam17 & 0.45 & 475 \\
\hline & & Beam 18 & 0.45 & 475 \\
\hline & & Beam19 & 0.45 & 475 \\
\hline & & Beam20 & 0.45 & 475 \\
\hline \multirow{5}{*}{5} & \multirow{5}{*}{$2 \%$ of $1 "$} & Beam21 & 0.4 & 425 \\
\hline & & Beam22 & 0.4 & 425 \\
\hline & & Beam23 & 0.375 & 400 \\
\hline & & Beam24 & 0.4 & 425 \\
\hline & & Beam 25 & 0.375 & 400 \\
\hline \multirow{5}{*}{6} & \multirow{5}{*}{$2.5 \%$ of $1 "$} & Beam26 & 0.375 & 400 \\
\hline & & Beam 27 & 0.375 & 400 \\
\hline & & Beam28 & 0.4 & 425 \\
\hline & & Beam29 & 0.4 & 425 \\
\hline & & Beam 30 & 0.4 & 425 \\
\hline \multirow{5}{*}{7} & \multirow{5}{*}{$3 \%$ of $1 "$} & Beam31 & 0.375 & 400 \\
\hline & & Beam32 & 0.375 & 400 \\
\hline & & Beam33 & 0.375 & 400 \\
\hline & & Beam34 & 0.375 & 400 \\
\hline & & Beam35 & 0.4 & 425 \\
\hline
\end{tabular}




\section{Experimental Results and Discussion}

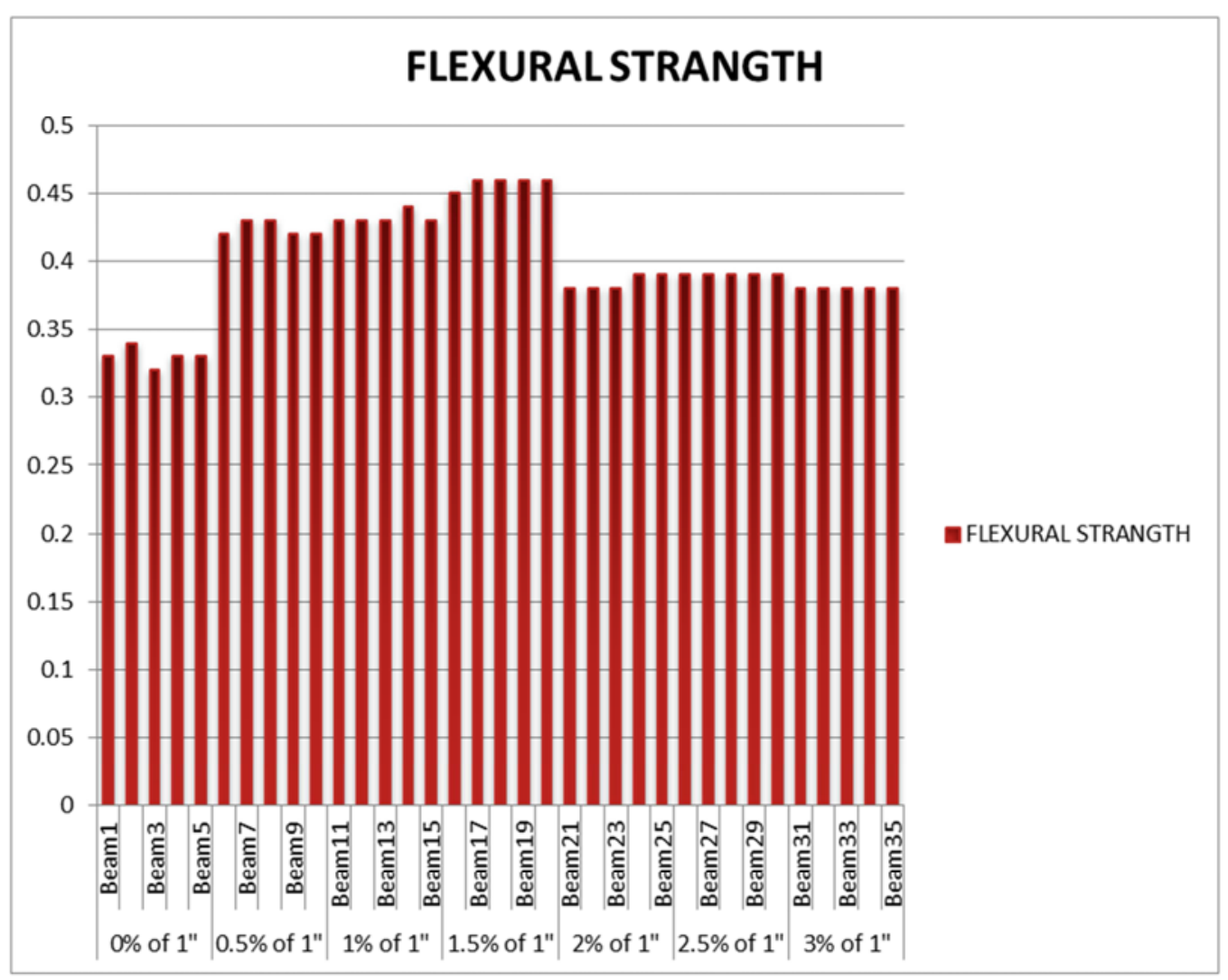

Figure 3. Graphical Representation of Flexural Strength of Beam having 01" WTSF.

Table 5. Average Flexural Strength of 1 "WTSFC.

\begin{tabular}{ll}
\hline \% age of WTSF & *Average Flexural Strength (Mpa) \\
\hline 0 & 0.33 \\
0.5 & 0.42 \\
1 & 0.43 \\
1.5 & 0.46 \\
2 & 0.39 \\
2.5 & 0.39 \\
3 & 0.38 \\
\hline
\end{tabular}

* Average of 5 samples

** Waste Tyre Steel Fibers

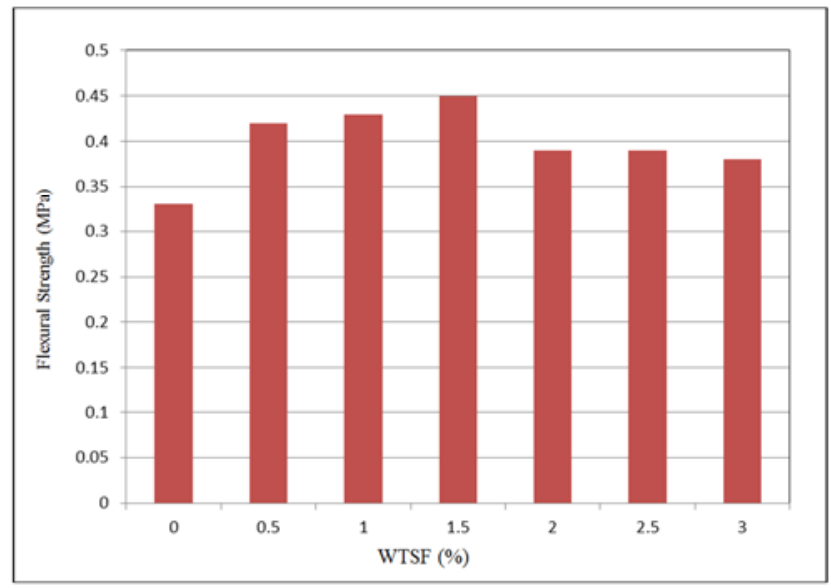

Figure 4. Average Graphical Representation of 1 " WTSFC.
At $1.5 \%$ of WTSF max Flexural Strength 0.45 Mpa was observed which is $20 \%$ more than the ordinary concrete

\subsection{Results}

Using 1 inch length of WTSF, At $1.5 \%$ of WTSF max Flexural strength $0.45 \mathrm{Mpa}$ was observed which is $20 \%$ more than the ordinary concrete.

\subsection{Utilization of Results}

By successful research the use of steel fibers reinforced concrete could therefore be used in a range of applications, such as repair of concrete, foundations, impact barriers, air port runways, drainage cover slabs, to minimize shear stresses, floors of heavy machinery and retaining walls.

In our country, currently there is need of tyre recycling industries to separate the rubber content from fibers to clean the surface of fibers from rubber and then cut in specified aspect ratio,

So, that these high strength steel fibers (inside tyres) could be utilized as secondary raw material in Civil Engineering purposes.

It is strongly suggested that the wasted tyres fibers used as secondary (raw) material in structural applications should not be extracted from the tyre chips by burning, it has two main reasons, first one is the decrease in tensile strength of fibers also loses its ductility and become of brittle nature. 


\section{References}

[1] T. S. Lok, and J. R. Xiao. (1999) 'Flexural Strength Assessment of Steel Fiber Reinforced Concrete" Journal of Materials in Civil Engineering: 188-196.

[2] Cengiz Duran Atis, Okan Karahan and Kamuran Ari et. al (2009) "Relation between Strength Properties (Flexural and Compressive) and Abrasion Resistance of Fiber (Steel and Polypropylene)-Reinforced Fly Ash Concrete" Journal of Materials in Civil Engineering ASCE: 402-408.

[3] M. A. Aiello, F. Leuzzi, G. Centonze, A. Maffezzoli (2009) "Use of steel fibers recovered from waste tyres as reinforcement in concrete: Pull-out behavior, compressive and flexural strength" Department of Innovation Engineering, University of Salento, via Monteroni, 73100 Lecce, Italy.

[4] S. K. Padmarajaiah, Ananth Ramaswamy (2002)."Flexural strength predictions of steel fiber reinforced high-strength concrete in fully-partially prestressed beam specimens." Department of Civil Engineering, IIT Roorkee, UP, Indiab Department of Civil Engineering, Indian Institute of Science, Bangalore 560012, India.

[5] Hamdy M. Mohamed, Radhouane Masmoudi. (2010) "Flexural strength and behavior of steel and FRP-reinforced concrete-filled FRP tube beams." Department of Civil Engineering, University of Sherbrooke, Quebec, Canada J1K 2R1.

[6] Su Tae Kang a, Bang Yeon Lee b, Jin-Keun Kim c, Yun Yong Kim. (2010) The effect of fiber distribution characteristics on the flexural strength of steelfiber-reinforced ultra high strength concrete." Structural Engineering \& Bridges Research Division, Korea Institute of Construction Technology.

[7] G. Centonze, M. Leone, M. A. Aiello, 2012. "Steel fibers from waste tires as reinforcement in concrete: A mechanical characterization." Department of Innovation Engineering, University of Salento, via Monteroni, 73100 Lecce, Italy Construction and Building Materials 36, 46-57.

[8] M. N. Soutsos, T. T. Le, A. P. Lampropoulos (2012). "Flexural performance of fiber reinforced concrete made with steel and synthetic fibers."Construction and Building Materials 36, 704 710.

[9] Singh S. P., Mohammadi Y., Madan S. K (2006). "Flexural fatigue strength of steel fibrous concrete containing mixed steel fibers." Journal of Zhejiang University SCIENCE A ISSN 1009-3095 (Print); ISSN 1862-1775 (Online) www.zju.edu.cn/jzus.

[10] D. V. Soulioti, N. M. Barkoula, A. Paipetis and T. E. Matikas (2011). "Effects of Fiber Geometry and Volume Fraction on the Flexural Behaviour of Steel-Fiber." Reinforced Concrete Blackwell Publishing Ltd j Strain (2011) 47, e535-e541 541 doi: $10.1111 / \mathrm{j} .1475-1305.2009 .00652$. 